\title{
L. K. Koegel and C. LaZebnik: Growing up on the Spectrum: A Guide to Life, Love, and Learning for Teens and Young Adults with Autism and Asperger's
}

\author{
Penguin, New York, 400 pp, \$26.96
}

\author{
Fred R. Volkmar
}

Published online: 9 July 2009

(C) Springer Science+Business Media, LLC 2009

With early diagnosis and more effective interventions, the outcome for children with autism has substantially improved over the last several decades. As progressively more adolescents with autism spectrum disorders have entered college and the work force there has been a great need for a practical, adolescent and parent friendly guide to the challenges that come with increased independence and self-sufficiency. This volume provides a highly readable and very valuable guide for adolescents and young adults, and their families.

Building on their successful earlier collaboration, Koegel and LaZebnik bring an important combination of perspectives to issues of adolescence and adulthood. The book is divided into several sections: an overview, a section on friendships, another on romantic relationships, school, beyond college, and improving daily life. The perspectives of the two authors, as parent and researcher, alternate along with practical examples of problems and solutions drawn from a range of individuals with autism spectrum disorders. Provision of actual experiences and practical solutions tremendously enrich this volume. The perspectives of the authors nicely complement each other as do the questions and answers and comments from Andrew, the son of one of the authors.

This book is both a pleasure to read and an invaluable resource for adolescents and young adults on the autism spectrum and their families.
F. R. Volkmar $(\square)$

Yale University, New Haven, CT, USA

e-mail: jaddeditor@yale.edu 